\title{
Towards sustainable energy utilisation: An analysis of various cooking fuel options in Malawi
}

\author{
Nkhonjera L. ${ }^{1 *}$, Hameer S. ${ }^{1}$ and Kosamu I. B. M. ${ }^{2}$ \\ ${ }^{1}$ Department of Sustainable Energy Science and Engineering, Nelson Mandela Institute of Science and Technology, P. \\ O. Box 447 Arusha, Tanzania. \\ ${ }^{2}$ Physics and Biochemical Sciences Department, University of Malawi - The Polytechnic, Private Bag 303, Blantyre 3 , \\ Malawi.
}

\begin{abstract}
In Malawi, nearly all (95\% rural and $55 \%$ urban) households depend on firewood and charcoal for cooking. Consequently, domestic cooking is contributing to unsustainable exploitation of forests which result into various adverse socioeconomic and environmental effects. On the other hand, recent scholarship has shown that cooking using other energy sources such as electricity, biogas, ethanol/gelfuel, liquefied petroleum gas, kerosene and jatropha oil is viable. The objective of this study was to find out if the available energy alternatives would be sustainably viable for cooking in Malawi. A sustainability analysis of the potential cooking fuels was conducted. It was found that a combination of electricity, ethanol/gelfuel, biogas, solar, and wood fuel (firewood and charcoal) from sustainably managed sources and use of energy efficient wood fuel stoves can provide sustainable energy for cooking in Malawi with wood fuel remaining dominant in the supply mix.
\end{abstract}

Key words: Sustainable energy, wood fuel, household energy, cooking, Malawi.

\section{INTRODUCTION}

It is reported that globally 1.4 billion people have no access to modern energy while 1.3 billion rely on traditional biomass (wood fuels, agricultural by-products and cow dung) as their source of fuel (United Nations, 2012). In sub-Saharan Africa, energy for cooking dominates in the total energy consumed, with $76 \%$ of the population relying on traditional biomass (International Energy Agency, 2006). Though biomass is a renewable source, the unsustainable exploitation in sub-Saharan Africa threatens the extinction of supply, human and ecosystem health, as well as the natural environment in general (Pimentel et al., 1991; Smith et al., 2000b). In Malawi, nearly all households depend on firewood and charcoal for cooking which translates to $95 \%$ of energy supply in rural households and $55 \%$ in urban households (Government of Malawi, 2003).
Nevertheless, there are several alternative fuels for cooking which include electricity, biogas, ethanol/gelfuel, liquefied petroleum gas, coal, solar, kerosene and jatropha oil. On the other hand, improved energy efficiency of biomass for cooking promotes sustainable energy usage. Biogas, solar, ethanol and gel fuel are viable cleaner energy alternatives for cooking in subSahara Africa (Schlag and Zuzarte, 2008).

Presently, cooking energy in Malawi is $97.2 \%$ from wood fuel, $2.6 \%$ grid electricity and the remainder from other sources (National Statistical Office, 2012). The sources of wood fuel are products from different forest and land tenure arrangements, which include government forest plantations and forest reserves, private forest plantations and indigenous wood (customary land). The 2010 estimates show that the supply of biomass is 2.7 
times the demand (Kambewa and Chiwaula, 2010). However, due to spatial distribution of biomass resources, the surplus biomass energy is not accessible to all parts of the country.

On the other hand, there is a potential of increasing sustainable electricity production. For instance, in 2013 electricity production is expected to increase by $64 \mathrm{MW}$ after the completion of Phase II of Kapichira hydro power plant (Sonani, 2013). The assessed potential sites for hydropower can yield $1670 \mathrm{MW}_{\mathrm{e}}$ but only $21 \%$ is currently exploited. A further $10 \mathrm{MW}_{\mathrm{e}}$ can be generated from ILLOVO sugar factories (which are located in the districts of Nkhotakota and Chikhwawa in central and southern Malawi respectively), and $100 \mathrm{MW}_{\mathrm{e}}$ from thinning and wood residues in Chikangawa plantations in northern Malawi's district of Mzimba (Government of Malawi, 2009). If all these options for sustainable sources of electricity are exploited, a share of electricity use for cooking can increase.

Annually Malawi produces 18.8 million litres of ethanol (MIPA, 2007), which is either used for industrial applications, blended with gasoline or exported. However, there is a potential of increasing ethanol production to contribute to the cooking fuel energy mix (Ethio Resource Group, 2007). Besides, Malawi has the potential of producing substantial amount of biogas from municipal biodegradable solid wastes generated at estimated rate of $0.78 \mathrm{~kg} / \mathrm{cap} / \mathrm{day}$ (van Beukering et al., $1999)$ by a total of about 1.6 million inhabitants in Lilongwe, Blantyre, Mzuzu and Zomba Cities (National Statistical Office, 2010). One kilogram of volatile solids in municipal wastes can generate $0.36 \mathrm{~m}^{3}$ of biogas at retention time of 25 days (Elango et al., 2007). Solar cooking technology has been in existence for long but the uptake of the technology is discouraging probably because of limitations of the available solar cooking technologies. Yet, some successful deployments of the solar cooking technologies are reported in literature (Solar Cooker International, 2003; Wilson and Green, 2000).

Like in many developing countries, key energy issues in the household sector of Malawi revolve around scarcity of energy supply to meet the demand. The supply constraint of cooking fuel emanating from diminishing resource base has become enormous. Forest clearing and over exploitation of biomass as a source of fuel reduced the areas of protected forest cover in Malawi from 45 to $21 \%$ in the last two and a half decades (MIPA, 2007). Each year 1.4 million cubic meters of wood are cleared for the production of charcoal (Kambewa et al., 2007). The rate of deforestation between 1990 and 2000 was estimated at an annual rate of $2.4 \%$. This is the tenth highest rate of deforestation in Africa and is significantly higher than both Africa's deforestation rate of $0.78 \%$ and the world's average deforestation rate of $0.22 \%$ (Kosamu, 2011).

Therefore, this study aims at finding sustainable and relevant energy alternatives capable of continuously meeting energy demand for cooking in Malawi. An analysis of the sustainability and relevance of alternative cooking fuels are also presented.

\section{METHODOLOGY}

This study relied mostly on secondary data from published literatures. In the analysis, yearly population $(P)$, energy supplies and the average annual energy demand $\left(E_{D}\right)$ for cooking are the variables while the average annual household energy demand per capita $\left(E_{D P C}\right)$ for cooking is considered constant for the entire modeling period. The $E_{D P C}$ is calculated by (1) which uses the 2010 values of average annual household energy demand $\left(E_{D H}\right)$ found in (Kambewa and Chiwaula, 2010), household size (HS), number of households $(H H)$ and $P$ (National Statistical Office, 2012). The $E_{D}$ in $n^{\text {th }}$ year $\left(\mathrm{E}_{\mathrm{D}, \mathrm{n}}\right)$ is evaluated using (2) in which $P_{n}$ is the projected population in $n^{\text {th }}$ year found in (National Statistical Office, 2010).

$$
\begin{aligned}
& E_{D P C}=\left(\frac{E_{D H} \times H S \times H H}{P}\right)_{2010} \\
& E_{D, n}=E_{D P C} \times P_{n}
\end{aligned}
$$

Malawi is endowed with coal, biomass (wood fuel, ethanol and gelfuel, biogas), hydropower, and solar. Nevertheless, coal is a finite resource, therefore, it is not considered in this analysis. Solar energy, despite being infinite and ubiquitous resource, has technological limitations when considered for cooking. Consequently, its inclusion in the analysis is projected to 2030 in which share of renewable energy in the energy mix is expected to increase to 8\% (Government of Malawi, 2003).

Subsequently, three scenarios are modeled. The first scenario is where the present energy mix for cooking remains constant for entire modeling period. In the second scenario, sustainable energy resources, currently not used for cooking are introduced at appropriate years during the modeling period. The last scenario is the modification of the second scenario such that effect of energy efficiency and population growth rate on $E_{D}$ is included. The percentage of wood fuel, grid electricity, ethanol/gelfuel, biogas, and solar in meeting $E_{D}$ are respectively denoted $f_{w}, f_{e}, f_{g}, f_{b}$, and $f_{s}$. Malawi in her energy policy of 2003 (Government of Malawi, 2003) focused that in 2020, a $7 \%$ of the total energy mix to come from liquid fuels (petroleum and biofuels) and $8 \%$ from other renewable (solar, wind, geothermal) by 2030. Thus in the second scenario, intervention of ethanol/gelfuel is introduced in 2020 and in 2030 and intervention of biogas and solar energy for cooking are introduced in 2030. Besides, it is focused that electrification rate in Malawi would be $30 \%$ by 2020 and $45 \%$ by 2040 (Millennium Challenge Account, 2009). Thus for these years, the share of electricity for cooking in the second and third scenarios are adjusted accordingly. Table 1 is the summary of the scenarios.

\section{Scenario 1}

The annual available wood fuel energy $\left(E_{w}\right)$ is estimated from forest cover $(F C)$ available for cooking. The available wood fuel energy for cooking in year 2010 is computed by (3) using the low heating values of wood (LHV) and available forest cover for cooking in that year. The $E_{w, 2010}$ is used as the basis for calculating the available wood fuel energy in the subsequent years. 
Table 1. Summary of Scenarios. (Please clarify the number in the Scenario).

\begin{tabular}{ccccccc}
\hline Scenario & Year & $\begin{array}{c}\text { Wood fuel } \\
(\%)\end{array}$ & $\begin{array}{c}\text { Electricity } \\
(\%)\end{array}$ & $\begin{array}{c}\text { Ethanol/gelfuel } \\
(\%)\end{array}$ & $\begin{array}{c}\text { Biogas } \\
(\%)\end{array}$ & $\begin{array}{c}\text { Solar } \\
(\%)\end{array}$ \\
\hline 1 & $2012-2050$ & $\mathrm{f}_{\mathrm{w} 1}$ & $\mathrm{f}_{\mathrm{e} 1}$ & $\mathrm{f}_{\mathrm{g} 1}$ & $\mathrm{f}_{\mathrm{b} 1}$ & $\mathrm{f}_{\mathrm{s} 1}$ \\
2 & $2012-2019$ & $\mathrm{f}_{\mathrm{w} 1}$ & $\mathrm{f}_{\mathrm{e} 1}$ & $\mathrm{f}_{\mathrm{g} 1}$ & $\mathrm{f}_{\mathrm{b} 1}$ & $\mathrm{f}_{\mathrm{s} 1}$ \\
2 & $2020-2029$ & $\mathrm{f}_{\mathrm{w} 2}$ & $\mathrm{f}_{\mathrm{e} 2}$ & $\mathrm{f}_{\mathrm{g} 2}$ & $\mathrm{f}_{\mathrm{b} 2}$ & $\mathrm{f}_{\mathrm{s} 2}$ \\
2 & $2030-2050$ & $\mathrm{f}_{\mathrm{w} 3}$ & $\mathrm{f}_{\mathrm{e} 3}$ & $\mathrm{f}_{\mathrm{g} 3}$ & $\mathrm{f}_{\mathrm{b} 3}$ & $\mathrm{f}_{\mathrm{s} 3}$ \\
3 & $2020-2050$ & & Reduced $A E D$ due to higher energy efficiency & \\
\hline
\end{tabular}

$$
E_{w, 2010}=F C_{2010} \times L H V
$$

The annual planting of trees and natural germination of vegetation regenerates the FC by a certain percentage. The 2012 to 2050 yearly replenishment percentages are adequately approximated to fit exponential distribution function of the kind $e^{x n}$ where $n$ corresponds to the year that is, $n=1$ in 2012 and $n=39$ in 2050 and $x$ is the parameter that determines the percentage in the final year. Therefore, the available wood fuel energy in $n^{\text {th }}$ year is calculated by (4) where $E_{w 1,(n-1)}$ and $E_{D,(n-1)}$ are respectively $E_{w}$ and $\mathrm{E}_{\mathrm{D}}$ of the previous year.

$$
E_{w 1, n}=E_{w 1,(n-1)} \times e^{x n}-f_{w 1} \times E_{D,(n-1)}, \quad 1 \leq n \leq 39
$$

\section{Scenario 2}

The available annual wood fuel energy $E_{w}$ for scenario 2 is evaluated using (5) which is the segmentation of (4) emanating from intervention of ethanol/gelfuel, solar and biogas that affect the value of $f_{w}$. The intervention of ethanol/gelfuel in 2020 changes $f_{w 1}$ to $f_{w 2}$. Similarly the intervention of solar and biogas in 2030 changes $f_{w 2} f_{w 3}$. The meanings of the contents of (5) are as previously defined.

$$
E_{w 2, n}=\left\{\begin{array}{l}
E_{w 2,(n-1)} \times e^{x n}-f_{w 1} \times E_{D,(n-1)}, 1 \leq n \leq 8 \\
E_{w 2,(n-1)} \times e^{x n}-f_{w 2} \times E_{D,(n-1)}, 9 \leq n \leq 18 \\
E_{w 2,(n-1)} \times e^{x n}-f_{w 3} \times E_{D,(n-1)}, 19 \leq n \leq 39
\end{array}\right.
$$

\section{Scenario 3}

The effect of energy efficiency is included in this scenario. The advocacy of energy efficient technologies and best practices are expected to increase the percentage of energy efficient households. The 2012 to 2050 yearly percentage of energy efficient households adequately fits exponential distribution function of the kind $e^{y n}-1$ where $n$ is as previously defined and ${ }^{y}$ is the parameter that is determined from the expected terminating percentage of energy efficient households in 2050. Consequently, (5) is modified to (6) to incorporate the effect of energy efficiency and population growth rate. The traditional biomass cooking stoves widely used in Malawi are of $15 \%$ efficiency (Government of Malawi, 2003), yet higher efficient biomass stoves are attainable. Hence, in (6), $\eta$ is the ratio of energy efficiency of conventional cooking stoves to that of higher efficient cooking stoves and $\mathrm{Y}$ is the population growth rate in percent. The other contents of (6) are as previously defined.

$E_{w 3}= \begin{cases}E_{w 3,(n-1)} \times e^{x n}-f_{w 1} \times\left[1-(1-\eta)\left(e^{v n}-1\right)\right](1+0.01 \gamma) E_{D,(n-1)}, & 1 \leq n \leq 8 \\ E_{w 3,(n-1)} \times e^{x n}-f_{w 2} \times\left[1-(1-\eta)\left(e^{v n}-1\right)\right](1+0.01 \gamma) E_{D,(n-1)}, & 9 \leq n \leq 18 \\ E_{w 3,(n-1)} \times e^{v n}-f_{w 3} \times\left[1-(1-\eta)\left(e^{y n}-1\right)\right](1+0.01 \gamma) E_{D,(n-1)}, & 19 \leq n \leq 39\end{cases}$

The annual available energy depends on population, proportion of the population that adapts high efficient cooking practices, stove efficiency and the woodfuel replenishment rate parameters. Therefore, iteration of Equation 6 for different combinations of these parameters determines the combination that offers optimum sustainable available energy.

Determination of $f_{w}, f_{e}, f_{g}, f_{b}, f_{s}$

Following the procedure that follows, Microsoft Excel is used to calculate the proportion of wood fuel, electricity, ethanol/gelfuel, biogas and solar in the total energy demanded for cooking.

1. Wood fuel and grid electricity meet the $E_{D}$. Hence $f_{w 1}+f_{e 1}=1$. From the integrated household survey (National Statistical Office, 2012), percentage of the number of households that use electricity for cooking was obtained which was then multiplied by $E_{D H}$ to obtain energy supplied by grid electricity which was eventually divided by $E_{D}$ to get $f_{e 1}$. Subtracting $f_{e 1}$ from 1 resulted to $f_{w 1}$.

2. The $E_{D}$ is met by wood fuel, electricity and ethanol/gelfuel such that $f_{w 2}+f_{e 2}+f_{g 2}=1$. Since ethanol/gelfuel is not currently used for cooking, its potential capacity available for cooking was obtained from (Ethio Resource Group, 2007). The potential capacity was then converted to available energy using the low heating values of ethanol. The ratio of calculated available energy to $E_{D}$ gave $f_{g 1}$. Ethanol/gelfuel for cooking is focused to be substantial by 2020 (Government of Malawi, 2003). Also in 2020, the electricity generation is envisaged to have increased (Millennium Challenge Account, 2009); therefore, the focused number of households using grid electricity for cooking is used to calculate $f_{e 2}$ using procedure in step 1 . Finally, $f_{w 2}$ is calculated from the values of $f_{\mathrm{e} 2}$ and $f_{g 2}$.

3 . The advancement of biogas and solar energy technologies is predicated to result into their substantial use for cooking by 2030 (Government of Malawi, 2003). The number of solar devices deployed determines the extent of utilization of the readily available solar resource. Hence, the value of $f_{s 3}$ is assigned a small value with an understanding that advanced and appropriate solar cookers 
Table 2. 2008 - 2050 Population Projection.

\begin{tabular}{cccccccccc}
\hline Year & $\begin{array}{c}\text { Population } \\
\text { (million) }\end{array}$ & Year & $\begin{array}{c}\text { Population } \\
\text { (million) }\end{array}$ & Year & $\begin{array}{c}\text { Population } \\
\text { (million) }\end{array}$ & Year & $\begin{array}{c}\text { Population } \\
\text { (million) }\end{array}$ & Year & $\begin{array}{c}\text { Population } \\
\text { (million) }\end{array}$ \\
\hline 2008 & 13.1 & 2017 & 17.4 & 2026 & 23.1 & 2035 & 30.3 & 2044 & 38.9 \\
2009 & 13.5 & 2018 & 17.9 & 2027 & 23.8 & 2036 & 31.2 & 2045 & 39.9 \\
2010 & 13.9 & 2019 & 18.5 & 2028 & 24.5 & 2037 & 32.1 & 2046 & 41 \\
2011 & 14.4 & 2020 & 19.1 & 2029 & 25.3 & 2038 & 33 & 2047 & 42 \\
2012 & 14.8 & 2021 & 19.7 & 2030 & 26.1 & 2039 & 34 & 2048 & 43 \\
2013 & 15.3 & 2022 & 20.4 & 2031 & 26.9 & 2040 & 34.9 & 2049 & 44.1 \\
2014 & 15.8 & 2023 & 21 & 2032 & 27.7 & 2041 & 35.9 & 2050 & 45.2 \\
2015 & 16.3 & 2024 & 21.7 & 2033 & 28.6 & 2042 & 36.9 & & \\
2016 & 16.8 & 2025 & 22.4 & 2034 & 29.4 & 2043 & 37.9 & & \\
\hline
\end{tabular}

Source: National Statistics Office (2010).

Table 3. Parametric values.

\begin{tabular}{cccccc}
\hline Parameter & Value & Parameter & Value & Parameter & Value \\
\hline$F C_{2010}$ & $116 \mathrm{Mt}$ & $f_{g 1}, f_{b 1}, f_{s 1}$ & 0 & $f_{w 3}(2040-50)$ & 0.845 \\
$L H V$ & $15.5 \mathrm{GJ} / \mathrm{kg}$ & $f_{w 2}$ & 0.917 & $f_{e 3}(2040-50)$ & 0.122 \\
$x$ & 0.0012 & $f_{e 2}$ & 0.081 & $f_{g 3}$ & 0.025 \\
$f_{w 1}$ & 0.974 & $f_{g 2}$ & 0.002 & $f_{b 3}$ & 0.006 \\
$f_{e 1}$ & 0.026 & $f_{w 3}(2030-39)$ & 0.886 & $f_{s 3}$ & 0.002 \\
\hline
\end{tabular}

would be at its inception. The per capita biogas produced from municipal wastes is determined from the product of estimated per capita biodegradable municipal waste generation and the specific biogas production per kilogram of volatile solids in municipal wastes. The projected urban population is used to calculate the total biodegradable waste generation. The calculated biogas production is then converted to energy using its LHV. The quotient of the biogas energy and $E_{D}$ yields $f_{b 3}$. The values of $f_{e 3}$ and $f_{g 3}$ are respectively calculated as in step 1 and step 2 . So $f_{w 3}$ is obtained from $f_{w 3}=1-f_{e 3}-f_{g 3}-f_{b 3}-f_{s 3}$.

Equations (2), (4), (5) and (6) are then simultaneously run in Microsoft Excel to obtain the yearly available wood energy from 2012 to 2050 for scenario 1,2 and 3 respectively. Subsequently, data outputs are presented in graphical form plotted in the same Microsoft excel.

\section{RESULTS}

The monthly household energy demand for cooking in Malawi is 1019 MJ (Kambewa and Chiwaula, 2010) with 2,742,456 households having an average household size of 4.6 people (National Statistical Office, 2009) and thus, using (1) the value of $E_{D P C}$ is $2.7 \mathrm{GJ}$. The population of Malawi increases from 13.1 million in 2008 to 45.2 million in 2050 as projected by National Statistics Office (2010) with in-between projected population as shown in Table
2. The population grows exponentially with a decreasing growth rate ranging from $3.2 \%$ in 2008 to $2.4 \%$ in 2050 . This translates to average population growth rate of $2.8 \%$ per annum.

Using the methods outlined earlier in this paper, and data from various literatures, the values of the parameters in (3) through (6) are tabulated in Table 3. The value of $x$ in the Table 3 is for equations (3) and (4) and it determines the exponential growth of woodfuel replenishment rate ranging from $0 \%$ in 2012 to $5 \%$ in 2050 yielding to an average replenishment rate of $2.4 \%$ per year.

For optimum condition in Equation (5), the value of $x, y$, $\eta$ and $y$ are respectively $0.0022,0.013,0.4$ and $2.03 \%$. This translates to mean woodfuel replenishment rate of about $4.7 \%$ per annum, $36 \%$ of the population utilizing stoves of $37.5 \%$ efficient while the rest of the population still uses traditional stoves and the mean annual population growth rate reduced to $2.03 \%$.

With an increasing population, outputs of equation (2) show an increasing annual energy demand as depicted by green and purple curves in Figure 1. The energy demand from scenario 3 (optimum case) is lower than that of scenario 1 because of the effects of reduced population and improved efficiency. Also plotted in Figure 
Available Energy and Energy Demand (2012-2050)

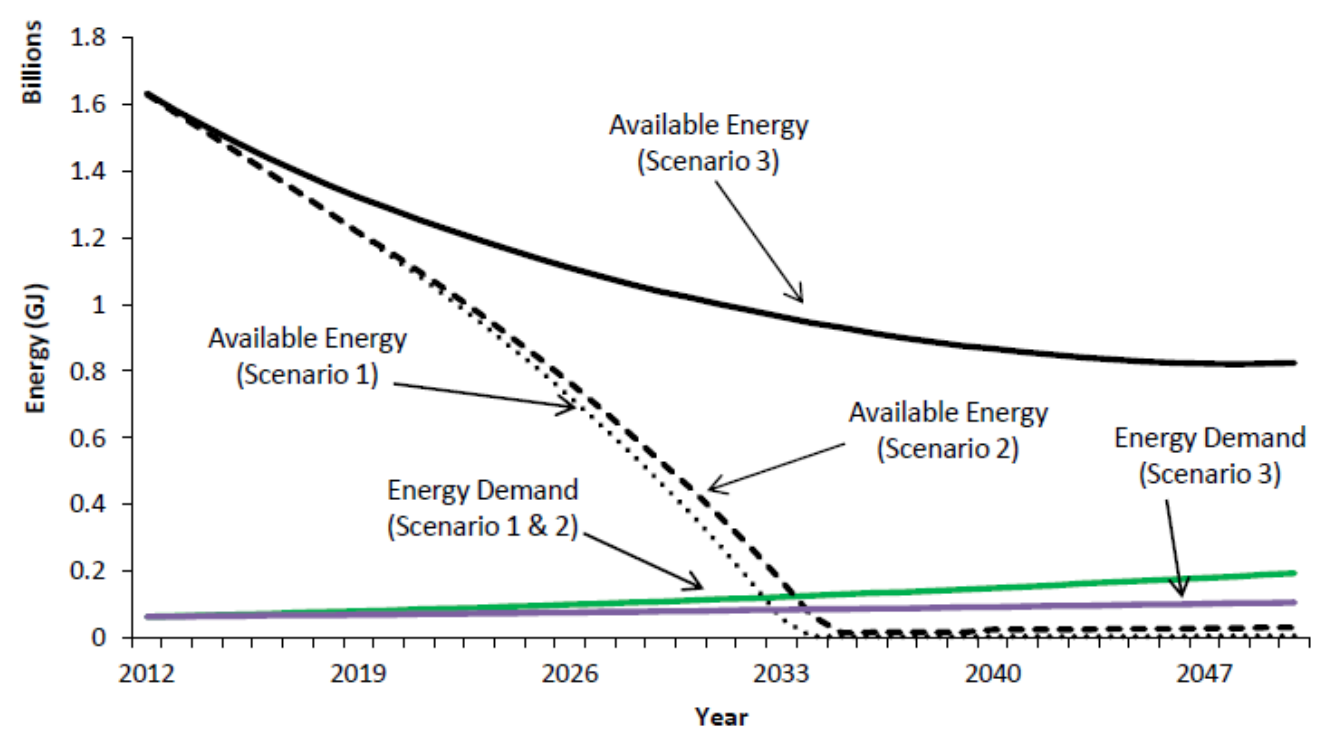

Figure 1. 2012 - 2050 annual available energy and the energy demand.

1 are total available energies for cooking for all three scenarios. The total available energy for cooking is the sum of available energy from wood fuel, grid electricity, ethanol, biogas and solar. For scenario 1 and 2, the total available energy diminishes so rapidly that it fails to meet the demand from around 2033. However, comparing scenario 1 and 2, the contribution from electricity, ethanol, biogas and solar extends energy availability by meager period of one year. Without woodfuel energy, the other sources are unable to meet the demand. Unlike scenario 1 and 2, in Figure 1, the curve of total available energy for the optimized scenario 3 denotes a slower reduction in energy availability until it stabilizes around 2040 with about eight times more energy than what is demanded. Figure 2 is the plot of available woodfuel energy for optimum parametric values $(x=0.0022, y=$ $0.013, \eta=0.4$ and $y=2.03 \%$ ) compared to available woodfuel energy for $\pm 5 \%$ of optimum parametric values. The green curve shows that when the optimum parametric values are increased, the available woodfuel energy would continually decrease as the optimized value and diverts upwards after about 14 years before it reaches a point when it will start increasing again. While the decreased parametric values would cause the available woodfuel energy to decrease continuously and diverts downwards from the optimized condition until it is depleted.

As shown in Figure 3, in year 2012 electricity contribution to cooking stood at $2.6 \%$ (National Statistical Office, 2012) and remained constant until 2020 when a projected contribution shall be at $8.1 \%$ emanating from the intervention of Millennium Challenge Account (MCA) project (Millennium Challenge Account, 2009). Also in 2020 , a $0.2 \%$ contribution from ethanol is anticipated
(Ethio Resource Group, 2007; Government of Malawi, 2003). It is computed that Malawi has a potential of producing $449280 \mathrm{~m}^{3} /$ day biogas from biodegradable municipal wastes. At a typical $60 \%$ methane content (Elango et al., 2007), this translates to annual energy of 426320GJ which represents $0.6 \%$ of the total energy demand. Authors found it difficult to quantify mathematically the contribution from solar energy. Hence a contribution of $0.2 \%$ from solar was assumed basing on the current penetration of solar PV. Both biogas and solar are expected to come into play by 2030 subject to effective implementation of renewable energy policies stipulated in Malawi Energy Policy (2003). In 2040 contribution from electricity is expected to be increased to $12.15 \%$ as a result of the implementation of MCA project. Contribution of each resource to the total energy demand is shown in Figure 3 from which it is seen that woodfuel contributes the greatest share. By 2040, contribution from electricity, ethanol, biogas and solar shall hover around $15 \%$.

Investigation of woodfuel availability in scenario 2 (average woodfuel replenishment rate of $2.4 \%$ and all households using $15 \%$ efficient traditional stoves) reveal that $20 \%$ of the available wood fuel is consumed within the first 20 years and the remaining $80 \%$ is rapidly consumed to extinction within the next 3 years (Figure 4a). For the optimized scenario, it is found that about $4 \%$ of the available woodfuel would be consumed in the first two years and another $6 \%$ would be consumed for the remaining 36 years (Figure 4b).

\section{DISCUSSION}

In Malawi, the future potential sustainable sources of 


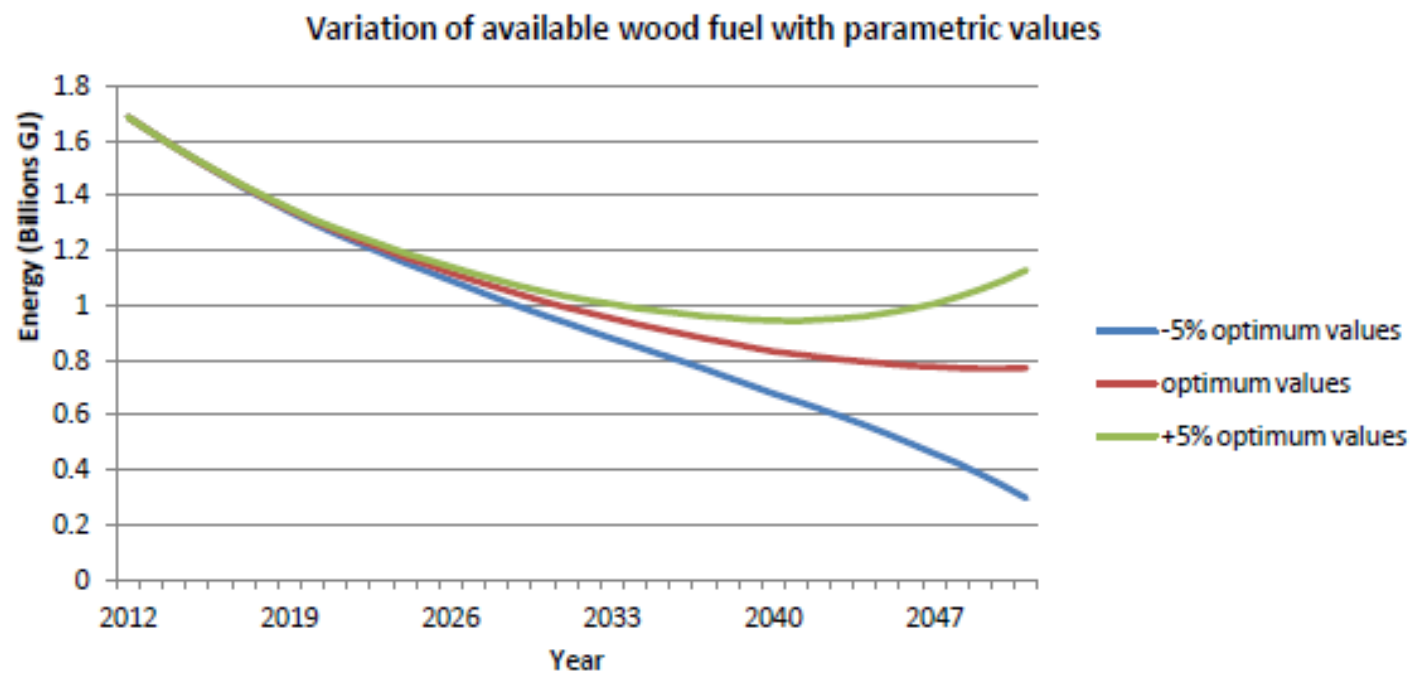

Figure 2. Variation of available woodfuel with the changing parametric valaues.

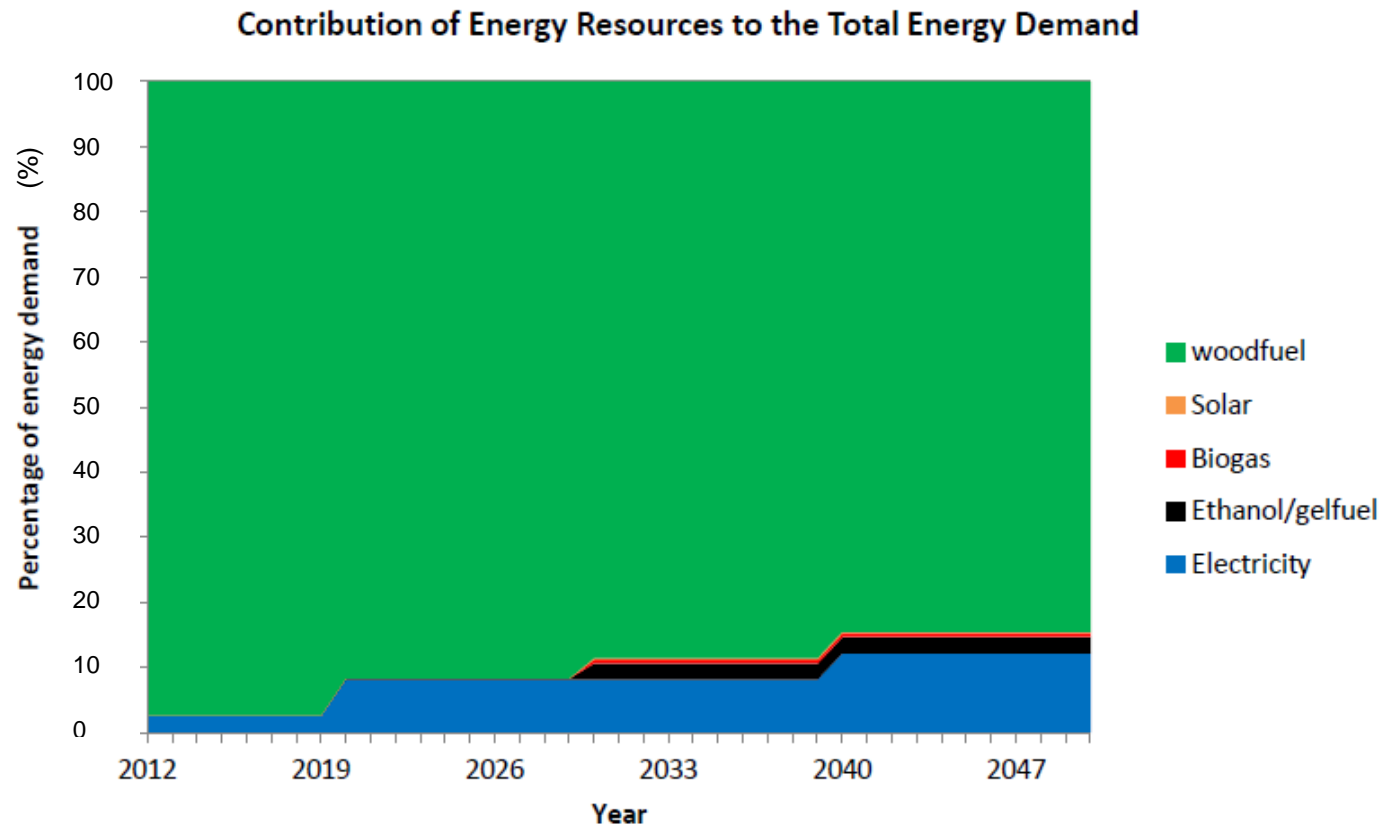

Figure 3. Contribution of energy resources to the total energy demand.

energy for cooking are sustainable woodfuel, electricity, ethanol/gelfuel, biogas and solar. However, for the period up to 2050, woodfuel replenished at mean annual rate of $2.4 \%$ with electricity, ethanol, biogas and solar mean contributions of $7.7,1.35,0.6$ and $0.2 \%$ respectively (scenario 2) would not sufficiently meet the demand after around 2033 because of extinction of woodfuel supply (Figure 4a). This poses a threat to the environment, as communities are likely to start exploiting the already vulnerable protected forest reserves. The diminishing forest reserves would expose the catchment areas, which results to scarcity of water resources. Additionally, this would soar the impact of climate change on the surrounding communities and would disturb ecosystem in the forest reserves. Additionally, extinction of wood fuel supply would create a higher demand than supply situation that results into escalating price of the fuel energy and facilitating importation of energy for cooking thereby lowering energy security and slowing down economic development. Therefore, the current production and consumption trends of energy for cooking are not economically and environmentally desirable. 
2012-2050 Proportions of Woodfuel available and Consumed (Scenario 2)

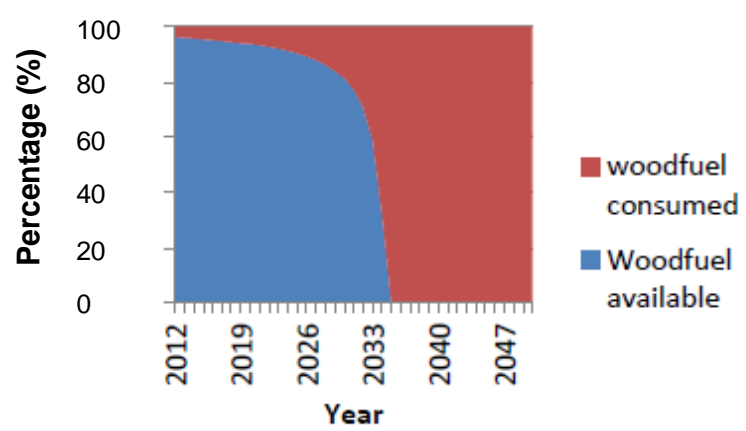

(a)
2012-2050 Proportion of Woodfuel Available and Consumed (Scenario 3)

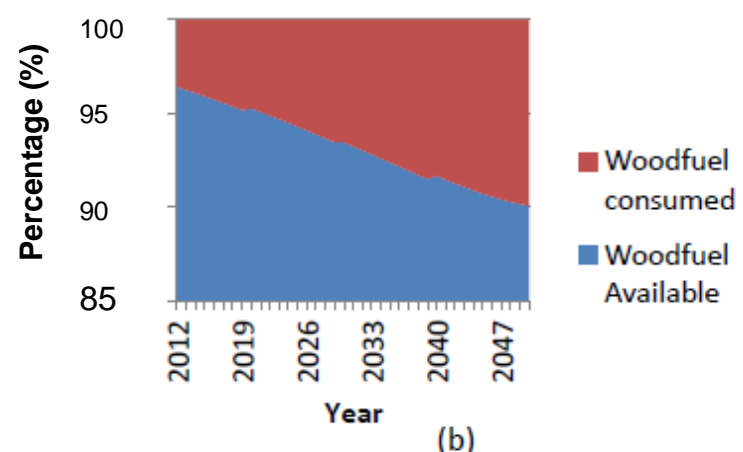

Figure 4. Proportions of wood fuel available and consumed (a) Scenario 2 (b) Scenario 3.

As expected, the increasing population growth increases energy demand (Figure 1) and thereby having a reduction effect on the available energy. On the contrary, increasing woodfuel replacement rate and energy efficiency practices reduces the energy demand and thus increasing the available energy. Balancing these factors yields that sustainability of available energy can be achieved when the mean annual population growth is reduced from the present 2.8 to $2.03 \%$ with mean annual woodfuel replenishment rate of $4.7 \%$ and $36 \%$ of the population using $37.5 \%$ efficient cooking practices.

The aforementioned optimum parameter values looks potentially realistic. For instance, the 2010 Malawi Demography and Health Report (National Statistical Office and ICF Macro, 2011) reports a fertility rate of $5.7 \%$ down from 6\% in 2004 and Malawi in her Millennium Goals and Development Strategy II (MGDS II) (Government of Malawi, 2012) strategize to manage population growth for sustainable social economic development through promotion of use of modern contraceptives. These suggest a possibility of reducing population growth rate that can eventually enable attainment of sustainability energy for cooking. Also in MGDS II and Biomass Strategy, Malawi strategize to enhance sustainable management of forest resources. In the Energy Policy (Government of Malawi, 2003) the promotion of energy efficient technologies is stipulated. On the other hand, efficiency of $37 \%$ and above for biomass, electric, ethanol and biogas stoves are commercially available. Therefore, implementation of the foregoing strategies and policies would make the corresponding optimized values achievable and thus accelerating the sustainable availability of energy for cooking.

Wood fuel would remain important for cooking in Malawi (Figure 3). Thus, authors recommend that the penetration of high efficient cookers and efficient practices of cooking should be given priority if sustainable energy for cooking is to be realized. Besides, policies that support communal woodlots and civic education to the communities should be developed and implemented. In addition, the fast growing and high-energy content species should be advocated. Further, the developed policies should motivate investors to grow and sustainably manage woodlots solely for cooking energy. The investor should process, in an efficient manner, the harvested wood to charcoal or wood chips for utilization in high efficient stoves. Increment of production capacity from electricity, ethanol, biogas and solar should be explored in order to balance the proportion of energy sources in the total cooking energy mix.

\section{Conclusions}

Wood fuel remains important for cooking in Malawi and it will keep on supplying up to $80 \%$ of the total energy. This study concludes that for the cooking energy supply to be sustainable in Malawi, it is required that at least $36 \%$ of the population would be using stoves with efficiency of $37.5 \%$ or above and at least $4.7 \%$ of the remaining forest cover available for cooking should be allowed to regenerate. Various interventions by the Malawi government and other key stakeholders in energy supply should therefore focus on achieving this energy switch. Public awareness on these issues is also crucial.

\section{REFERENCES}

Elango D, Pulikesi M, Baskaralingam P, Ramamurthi V, Sivanesan S (2007). Production of biogas from municipal solid waste with domestic sewage. J. Hazard. Mater. 141:301-304.

Ethio Resource Group (2007). Feasibility study for the use of ethanol as the household cooking fuel in Malawi. UNDP, Lilongwe, Malawi.

Government of Malawi (2003). National Energy Policy. Government Press, Lilongwe, Malawi. 
Government of Malawi (2012). Malawi Growth and Development Strategy II (2011-2016) Government Press, Lilongwe, Malawi.

Governmet of Malawi (2009). Malawi Biomass Strategy. Government Press, Lilongwe, Malawi.

International Energy Agency (2006). World Energy Outlook 2006: Energy for cooking in developing countries. IEA, Paris, France.

Kambewa P, Mataya B, Sichinga K (2007). Charcoal: The reality - A study of charcoal consumption, trade and production in Malawi. Small and Medium Forestry Enterprise. 21. International Institute of Environment and Development, London, UK.

Kambewa P, Chiwaula L (2010). Biomass energy use in Malawi. . International ESPA workshop on biomass energy, 19-21 October 2010, Parliament House Hotel, Edinburgh.

Kosamu IBM (2011). Environmental impact assessment application in infrastructural projects in Malawi. Sustain Sci. 6:51-57.

Millennium Challenge Account (2009). Compact Program for the Government of the Republic of Malawi $(2011-2016)$ : Concept Paper for the Energy Sector. Millennium Challenge Account-Malawi Country Office, Lilongwe, Malawi.

MIPA (2007). Investors Guide to Malawi. Government Press, Lilongwe, Malawi.

National Statistical Office (2010). The Population Projection. Government Press, Zomba, Malawi.

National Statistical Office and ICF Macro (2011). Malawi Demographic and Health Survey 2010. National Statistical Office and ICF Macro, Zomba, Malawi and Calverton, Maryland, USA.

National Statistical Office (2012). Integrated Household Survey 20102011. Government Press, Zomba, Malawi.

Pimentel D, Floyd B, Teel W, Bourn J (1991). Deforestation,Biomass Depletion, and Land Degradation Linkages to Policy Reform in SubSaharan Africa. In Policy Reform and Natural Resource Management in Sub-Saharan Africa, James L, Steven K editors. College of Agriculture and Life Sciences, Cornell University, Ithaca, NY. pp. 3391.
Schlag N, Zuzarte F (2008). Market Barriers to Clean Cooking Fuels in Sub-Saharan Africa: A Review of Literature. Stockholm Environment Institute, Stockholm, Sweden.

Smith KR, Uma R, Kishore VVN, Junfeng Z, Joshi V, Khalil MAK (2000b). Indoor air pollution in developing countries and acute lower respiratory infections in children. Thorax 55.

Solar Cooker International (2003). Solar Cooker Review. Accessed on June 7 Access, 2003, from: http://solarcooking.org/newsletters/scrmar03.htm.

Sonani B (2013). Kapichira II ready August 2013. Accessed on February 3 Access, 2013, from: Nation Online. http://mwnation.com/business-news-the-nation/6332-kapichira-iiready-august-2013.

United Nations (2012). 2012 International year of sustainable energy for all. . Accessed on June 5 Access, 2012, from: http://www.un.org/en/events/sustainableenergyforall/background.sht $\mathrm{ml}$.

van Beukering P, Sehker M, Reyer GR, Kumar V (1999). Analysing urban solid waste in developing countries: A pespective on Bangalore, India. Institute for Social and Economic Change (ISEC), Nagarbhavi, Bangalore, India.

Wilson M, Green MV (2000). The feasibility of introducing solar ovens to rural women in Maphephethe. Tydskrif vir Gesinsekologie en Verbruikerswetenskappe. 28. 